$\mathbf{R}_{\text {ESEARCH }} \mathbf{P}_{\text {APER }} \longrightarrow \begin{aligned} & \text { FOOD SCIENCE } \\ & \text { RESEARCH JOURNAL }\end{aligned}$

\title{
Development of raw jackfruit based noodles
}

\author{
Veena Kumari, Suma Divakar, Mary Ukkruu and P.V. Nandini
}

Underexploited jackfruit can be better utilised, if consumer acceptable products like noodles can be prepared from this fruit. Jackfruit bulbs and seeds were subjected to different treatments for preparation of flour. Bulbs and seeds were standardised for optimum width, blanching, immersion in different media, drying and milling. Composite flour was prepared by mixing refined flour, bulb flour and seed flour in different combination (40:30:30, 50:25:25, 50:30:20, 50:40:10, 50:10:40, 50:20:30). Noodles were extruded from these combinations. Noodles were evaluated for sensory parameters. Sensory scores indicated that combinations $\mathrm{T}_{5}(50: 10: 40)$ and $\mathrm{T}_{6}(50: 20: 30)$ were highly acceptable. Therefore noodles prepared with substituted jackfruit flour were found to be feasible. This nutrient rich noodles will be good source of instant food for all age group people.

Key Words : Jackfruit, Bulb, Seed, Composite flour, Noodle

How to cite this article : Kumari, Veena, Divakar, Suma, Ukkruu, Mary and Nandini, P.V. (2015). Development of raw jackfruit based noodles. Food Sci. Res. J., 6(2): 326-332. 